УДК 629.78

\title{
СТОХАСТИЧЕСКАЯ ОЦЕНКА ДИНАМИЧЕСКИ ИЗМЕНЯЮЩИХСЯ ПАРАМЕТРОВ ОРИЕНТАЦИИ ОБЪЕКТА ПО СПУТНИКОВЫМ ИЗМЕРЕНИЯМ
}

\author{
ЛУКАСЕВИЧ В. И. ${ }^{1}$, КРАМАРОВ С. О. ${ }^{2}$, СОКОЛОВ С. В. ${ }^{3}$ \\ ${ }^{1}$ ОАО Центральный институт по проектированию машиностроительных предприятий, \\ Россия, Москва, 129626, пр-т Мира, 102, корп. Б \\ ${ }^{2}$ Институт управления, бизнеса и права, Россия, \\ Ростов-на-Дону, 344068, пр-т М. Нагибина, 33а/47 \\ ${ }^{3}$ Ростовский государственный университет путей сообщения, \\ Россия, Ростов-на-Дону, 344038, пл. Ростовского Стрелкового Полка Народного Ополчения, 2
}

\begin{abstract}
Аннотация. Решена задача апостериорного оценивания динамически изменяющихся параметров углового движения объекта по спутниковым измерениям. Показаны преимущества применения методов стохастической нелинейной динамической фильтрации перед одномоментными измерениями. Приведен пример, иллюстрирующий эффективность предложенного подхода
\end{abstract}

Ключевые слова: стохастическая фильтрация; инвариантная модель углового движения; спутниковые навигационные измерения; уравнения наблюдения; параметры вращения

\section{ВВЕДЕНИЕ}

Полное решение навигационной задачи подвижного объекта всегда предполагает определение параметров не только линейного движения, но и углового. В связи с этим доведение точности позиционирования объектов за счет использования спутниковых навигационных систем (СНС) до субсантиметрового диапазона [1-3] выдвигает в качестве задачи следующего этапа повышение точности спутникового определения параметров углового движения до значений, характерных для современных углоизмерительных систем геодезического класса [3-11].

В настоящее время все методы определения ориентации с помощью $\mathrm{CHC}$ возможно разделить на два класса: определение ориентации по предварительно найденным базовым векторам [9-16] и непосредственное определение углов ориентации $[11,12,17]$. Для всех этих методов характерно использование одномоментных измерений по базовым векторам с последующей их обработкой традиционными статистическими алгоритмами. Это не позволяет учесть особенности динамики вращения конкретного объекта и обеспечить требуемую точность оценки для средне- и высокодинамичных вращающихся объектов, а также в полной мере использовать методы современной теории стохастической фильтрации, обеспечивающие возможность оптимального оценивания угловых параметров с произвольной динамикой их изменения.

В [18] сделана попытка применения методов стохастической оптимальной фильтрации для оценки параметров пространственной ориентации объекта на основе обработки измерений псевдодальностей и псевдофаз, но при комплексировании СНС с инерциальной системой. Временная фильтрация в этом случае 